\title{
Arte urbano: entre la disidencia y la institucionalización. El caso de la ciudad de Valencia
}

\author{
Gerardo Jesús García Olivares | Gestor cultural \\ URL de la contribución <www.iaph.es/revistaph/index.php/revistaph/article/view/4900>
}

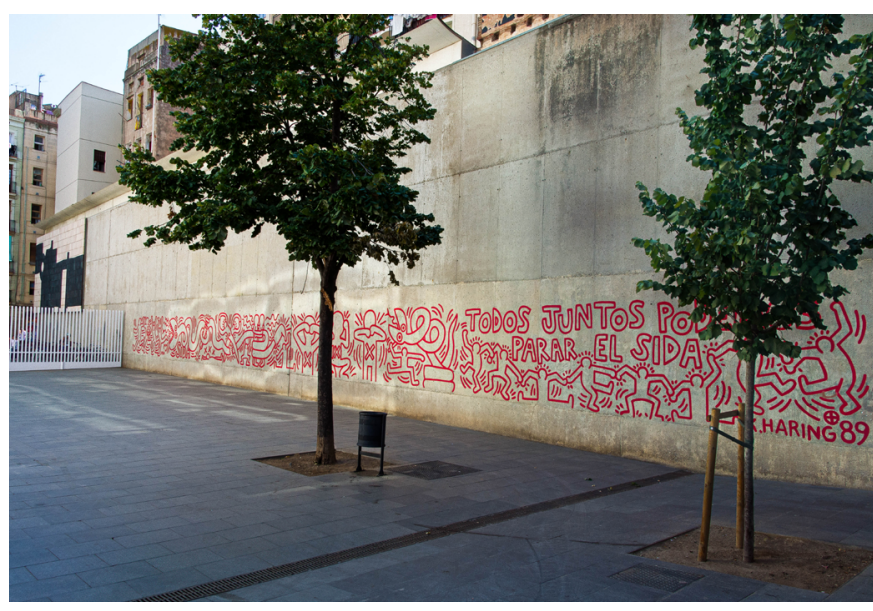

Todos Juntos Podemos Parar El Sida, mural que Keith Haring en el barrio del Raval en 1989 | foto John Weiss

El 27 de febrero de 1989, el muralista y activista norteamericano Keith Haring pintó en el barrio del Raval de Barcelona el mural Todos juntos podemos parar el sida. La obra nacía en medio de otra pandemia que causó la muerte del propio Haring en 1990. En el año 2014, el Museo de Arte Contemporáneo de Barcelona (MACBA) llevó a cabo la restitución de la obra, tras un acuerdo con la Keith Haring Foundation. Para ello se hizo un cuidadoso estudio de los materiales empleados, se calcaron los restos del original y se reprodujo en un muro contiguo al museo. Esta intervención plantea la reflexión sobre los alcances del arte urbano, sobre la volatilidad o no de su existencia, la intervención de las instituciones para garantizar su permanencia y si estas actuaciones producen su desnaturalización.

Conceptos como bombing, grafiti, mural, tag, stencil, esculturas, arte textil o póster forman parte del léxico común de estos artistas que, a menudo, transitan entre la disidencia y la institucionalización de su obra. No todo

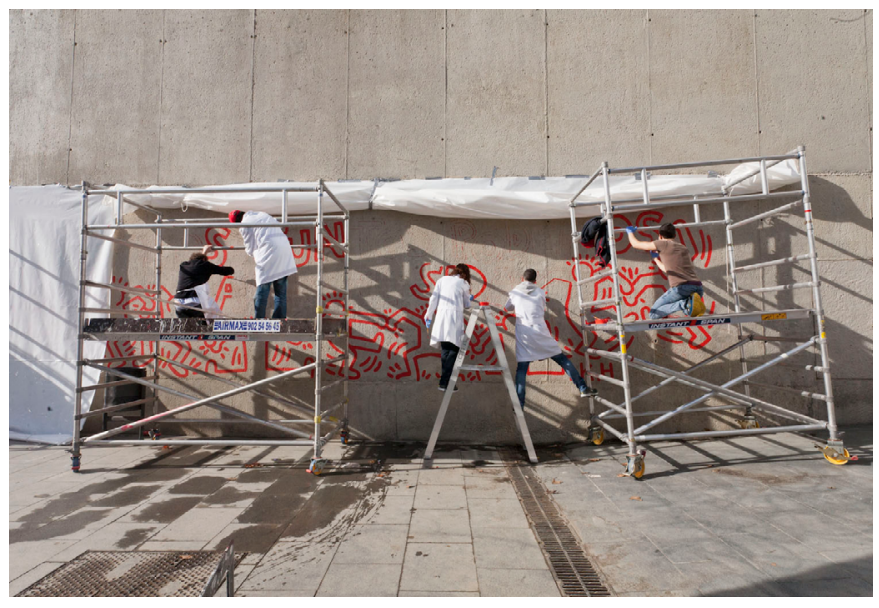

Restauradores del MACBA trabajan en el mural en 2014 | foto Museu d'Art Contemporani de Barcelona

el arte urbano es disidente; se tiende a confundir términos. No resultan equiparables un mural pagado por un ayuntamiento, que un bombing urbano. Los autores de este segundo tipo de expresiones asumen con naturalidad su carácter efímero y disidente, bien por la desaparición del soporte, por repintes de ellos o de otros artistas o por la eliminación por la Administración en el intento de hacer las ciudades lo más asépticas posibles, al considerar la temática incómoda. El soporte es lo que menos importa; pero el lugar -la ciudad- lo acerca de manera tangencial a los principios del movimiento supports-surfaces de mediados del siglo XX.

La ciudad de Valencia ha visto transformado el degradado centro histórico del barrio del Carmen en una verdadera galería de arte urbano al aire libre. El fenómeno se encuentra más activo que nunca y sorprende la diversidad de propuestas que le dan carácter al barrio y humanizan sus paredes. Algunos artistas han pasado de componer su obra en la clandestinidad de la noche y con 


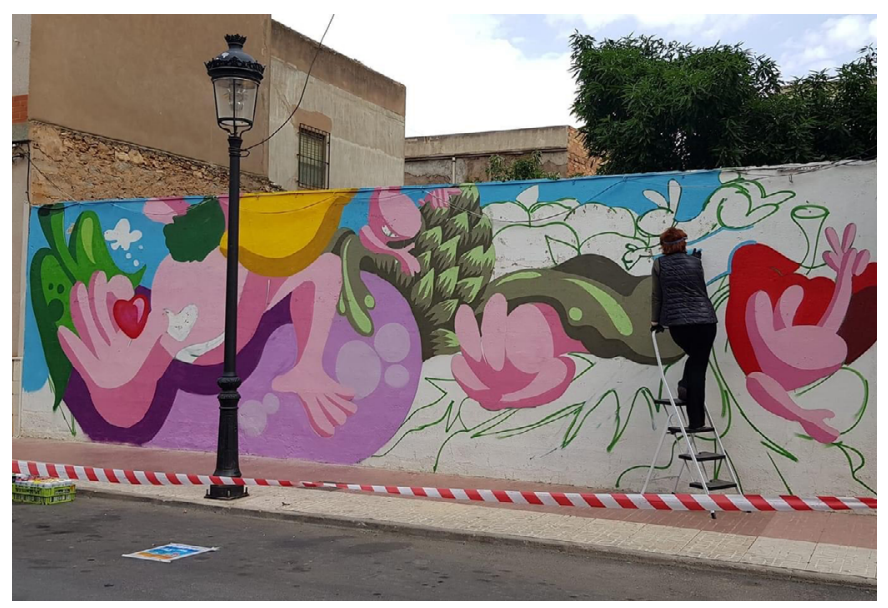

Mural de Barbiturikills | foto Barbiturikills

la complicidad de otros artistas constituidos en brigadas urbanas para poder alertar sobre la presencia policial, a ser reconocidos. $Y$ aunque han tenido que afrontar sanciones administrativas, hoy han consolidado su estilo y obra, y la han llevado a galerías de arte o museos. También han realizado murales por encargo de corporaciones locales o campañas publicitarias como la desarrollada por Barbiturikills ${ }^{1}$ a favor de la utilización de la mascarilla para frenar la expansión de la COVID-19.

El nivel de institucionalización y de apropiación simbólica de este arte que hacen museos, ayuntamientos o galerías resulta significativo. Así, dentro del Centro del Carmen de Cultura Contemporánea (CCCC), se pueden observar obras de artistas como David de Limón, Freskales o la Nena Wapa y, en el muro colindante con el Instituto Valenciano de Arte Moderno (IVAM), del artista Escif.

Con ello se somete esta modalidad de arte a una vigilancia institucional, sobre la que se ha de reflexionar, ya que el museo, como señala Pau Preciado, es una institución de vigilancia cultural. Las obras expuestas en museos pierden su carácter disidente y se transforman en algunos casos en inocuas. Algunos artistas se reservan la pared de la ciudad lejos de la mirada panóptica del espacio-museo para temas de actualidad, que requieren la mirada subversiva del arte, como en el caso de Warx o Escif, críticos con la crisis de los refugiados o la corrup-

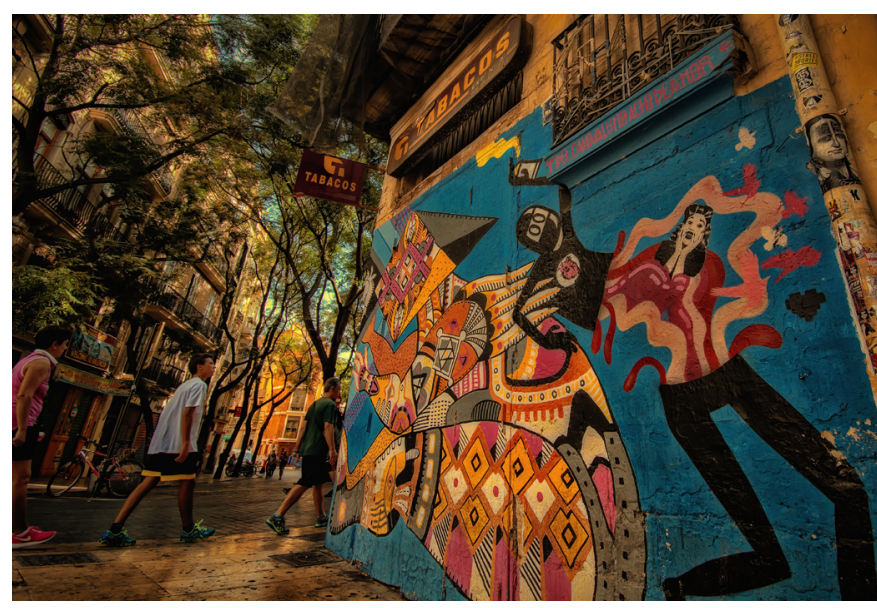

Mural de David de Limón, la Nena Wapa y Disneylexya | foto Derek Rankine

ción. O Barbiturikills, que desde su mirada feminista lleva a la calle temas como la desigualdad de género. Si el cartel en su momento fue un "grito en la pared", como proponía Josep Renau, hoy el arte urbano no institucionalizado no solo recupera este lema, sino que promueve cierta reflexión sobre algunos temas ausentes en galerías o museos.

La institucionalización de esta práctica ha llegado a tal punto que algunos artistas han colaborado en la construcción de la Falla del Ayuntamiento de Valencia. Las fallas son la fiesta más importante de la ciudad, consideradas por la UNESCO Patrimonio Inmaterial de la Humanidad. A partir de invitar al artista Miguel Okuda en el año 2018, le han seguido Pichiavo, en el 2019; Escif, en el 2020; y en el 2021, Dulk. Todos son hombres lo que evidencia la alta masculinidad dentro de este género, aunque hay mujeres que también destacan como Barbiturikills, La Nena Guapa, Julieta XLF o Hyuro. Quizás este nivel de masculinización en el arte urbano se deba a las mismas causas que se dan en el arte en general, aumentadas por la características propias de la práctica. Aunque hay artistas mujeres que reconocen la calle como un espacio de disidencia machista.

El arte urbano cumple los requisitos del arte líquido propuesto por Bauman, ya que se centra en acontecimientos pasajeros de gran impacto social. El arte como 


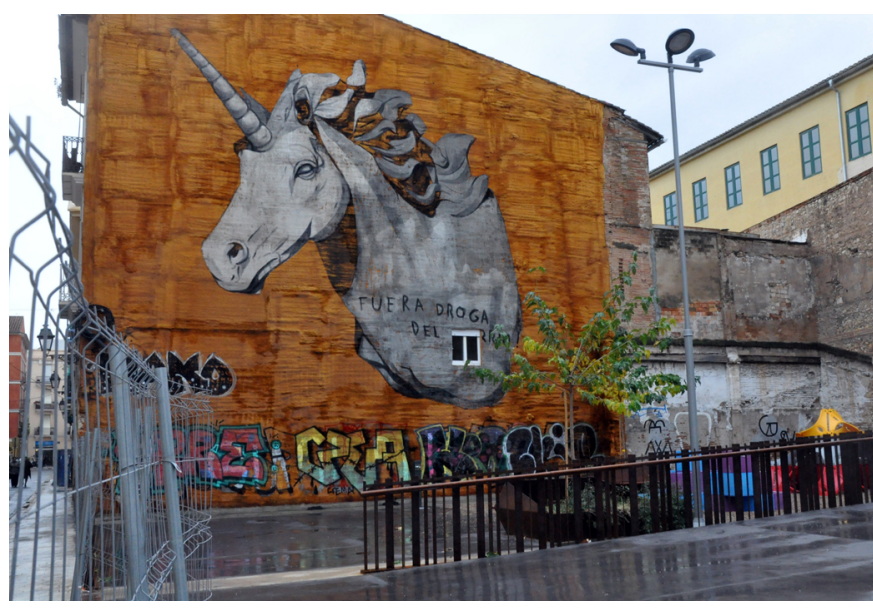

Mural de Escif | foto jaime.silva

acontecimiento y no el arte como obra, propio de esta modernidad líquida. Lo importante no es el soporte ni su permanencia, como sucedía en la era sólida, sino el momento de su creación, lo efímero y su pertinencia social y política. Además algunos artistas reconocen lo efímero como algo natural, casi una condición definitoria y necesaria para seguir produciendo obra nueva.

La consideración del arte urbano como patrimonio debería desprenderse de aspectos propios del arte de la época sólida, como el soporte, la continuidad, la permanencia, la autoría, con especial consideración de aspectos como la subalternidad, el anonimato, la pertenencia al espacio público, la creación colectiva y, por supuesto, la condición efímera. Esta patrimonialización debería mirar al proceso que ha llevado a las fiestas populares a ser consideradas como patrimonio inmaterial, ya que poseen los mismos puntos en común. Se debería, asimismo, evitar la tradicionalidad forzada y el relativo esencialismo identitario que se le atribuyen en ocasiones a algunas fiestas. Querer restaurarlo, consolidarlo, arrancarlo de las calles, vincularlo solo a una ciudad y llevarlo al museo supone ir contra su propia esencia.

Si el arte urbano en todas sus variantes se aparta de lo pulido, lo liso, lo impecable, como marcas de identidad del arte de nuestra época (Han 2015) y en él no importa la permanencia (Bauman 2007), rescata lo colectivo,

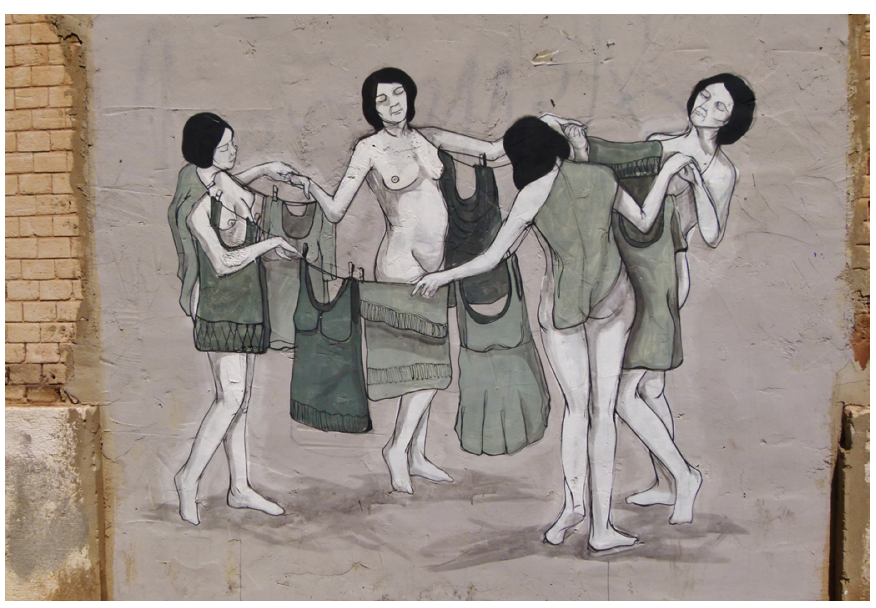

Mural de Hyuro | foto Antonio Martín Segovia

la disidencia, lo efímero y hasta el anonimato. La patrimonialización supone un esfuerzo artificioso para darle continuidad material; en todo caso bienvenida su valoración, siempre que sea como patrimonio inmaterial. Valga como ejemplo el caso del mural de Haring.

\section{NOTAS}

1. Mi agradecimiento a los artistas Barbiturikills, David de Limón y Alfredo Solaz de la Sabotage Gallery por concederme sendas entrevistas.

\section{BIBLIOGRAFÍA}

- Bauman, Z. (2007) Arte, ¿líquido? Madrid: Sequitur

- Grau Rebollo, J (2012) Antropología audiovisual reflexiones teóricas. Alteridades, n. ${ }^{\circ} 43$, pp. 161-175. Disponible en https://alteridades.izt.uam.mx/index.php/Alte/article/view/106 [Consulta: 12/04/2021]

- Han, B. C. (2015) La salvación de lo bello. Barcelona: Herder

- Kolossa, A. y Haring, K. (2004) Haring. Köln: Taschen 